\title{
A fresh look at the predictors of naming accuracy and errors in Alzheimer's disease
}

Fernando Cuetos*, Javier Rodríguez-Ferreiro**, Karen Sage*** \& Andrew W. Ellis****

*University of Oviedo

**University of Barcelona

***University of Manchester

****University of York

Address for correspondence:

Fernando Cuetos

Facultad de Psicología

Universidad de Oviedo

Plaza Feijoo, s/n

33003 Oviedo

Spain

Phone: 34985103283

Email: fcuetos@uniovi.es 
Abstract

In recent years a considerable number of studies have tried to establish which characteristics of objects and their names predict the responses of patients with Alzheimer's disease (AD) in the picture naming task. The frequency of use of words and their age of acquisition (AoA) have been implicated as two of the most influential variables, with naming being best preserved for objects with high frequency, early acquired names. The present study takes a fresh look at the predictors of naming success in Spanish and English AD patients using a range of measures of word frequency and AoA along with visual complexity, imageability and word length as predictors. Analyses using generalized linear mixed modelling found that naming accuracy was better predicted by AoA ratings taken from older adults than conventional ratings from young adults. Older frequency measures based on written language samples predicted accuracy better than more modern measures based on the frequencies of words in film subtitles. Replacing adult frequency with an estimate of cumulative (lifespan) frequency did not reduce the impact of AoA. Semantic error rates were predicted by both written word frequency and senior AoA while null response errors were only predicted by frequency. Visual complexity, imageability and word length did not predict naming accuracy or errors.

Key words: picture naming, Alzheimer's disease, age of acquisition, word frequency, cumulative frequency 
Early in the progression of Alzheimer's disease (AD), patients begin to experience difficulty remembering the names of objects and people. Those problems are normally attributed to deterioration of semantic (rather than episodic) memory representations (Hodges \& Patterson, 1995; Hodges, Graham, \& Patterson, 1995; Hodges et al 1996). The task of object naming is sensitive to impairment and is frequently used in the early diagnosis of AD (Albert et al., 2001, Cuetos, Rodríguez-Ferreiro, \& Menéndez, 2009, Vogel et al., 2005). The task may also be presented at intervals in order to monitor the progression of patients (Barbarotto, et al, 1998, Cuetos, Gonzalez-Nosti, \& Martinez, 2005, Lambon Ralph, Patterson, \& Hodges, 1997). Even in the later stages of the disease, patients may remain able to name at least some object pictures. Thus, Cuetos et al. (2005) found that patients with an average MMSE of 16.9 managed to name $72 \%$ of 100 pictures set. Two years later, when the MMSE had declined to 11.1, they were still able to name only $50 \%$ of the same pictures.

At a given stage in the progression of the disease, different patients tend to find the same objects relatively easy or difficult to name. This consistency across patients makes it possible to investigate the properties of objects and their names that influence naming success. Two factors that have been implicated in several previous investigations of naming in $\mathrm{AD}$ are the frequency of occurrence of object names in the language and the age of acquisition of those names, with studies reporting better naming of objects with high than low frequency names (Barker \& Lawson, 1968; Kirshner, Webb, \& Kelly, 1984; Rodríguez-Ferreiro et al., 2009; Tippett et al., 2007) and better naming of object with names acquired in early childhood than names acquired in later childhood or adulthood (Cuetos et al., 2005; Forbes-McKay, Ellis, Shanks, \& Venneri, 2005; Gale et 
al., 2009; Holmes, Fitch \& Ellis, 2006; Kremin et al., 2001; Rodriguez-Ferreiro et al., 2009; Silveri et al., 2002; see Ellis, 2011, for a review).

The results from these studies have not, however, produced uniformly consistent results. To the best of our knowledge, every study that has looked for an effect of AoA on naming in $\mathrm{AD}$ has found one, but the effect of frequency have been inconsistent. For example, while Rodríguez-Ferreiro et al. (2009) and Tippett et al. (2007) reported independent effects of AoA and word frequency on object naming in AD patients, Cuetos et al. (2005) and Silveri et al. (2002) found only effects of AoA. One issue may be to do with the quality and appropriateness of the measures of word frequency employed. Traditional measures of word frequency are based on samples of written language derived from newspapers, magazines, books, etc. It is very likely that the vocabulary of everyday domestic life is under-represented in such samples, including the names of items of clothing, furniture, food and similar items that feature prominently in tests of object naming. The CELEX database (Baayen, Piepenbrock, \& van Rijn, 1993) includes measures of both written and spoken word frequency, but the spoken language samples come from formal discussions, so the vocabulary of everyday life may again be under-represented. New, Brysbaert, Veronis, and Pallier (2007), Brysbaert and New (2009) and Cuetos, González-Nosti, Barbón and Brysbaert, 2011) have recently explored the use of subtitles from films and television programmes as an alternative source of language samples, arguing that these provided a closer match to everyday language experience. Subtitle frequencies were shown to predict adult lexical decision speed and accuracy better than alternative measures based on samples of written language. AoA continues to be a significant predictor of lexical decision and word naming speed even when subtitle frequency is controlled (Brysbaert \& Cortese, 2011). Most studies of adult word recognition are, however, conducted using young 
adults (typically university students) as participants. Inspection of Tables 6 and 7 from Brysbaert and New (2009) shows that English subtitle frequencies were considerably better at predicting the lexical decision speed and accuracy of young adults than older adults (taken from Balota et al., 2004, 2007). The same was true of traditional frequency measures, but to a lesser degree. One possibility that will be explored here is that subtitle frequencies provide a closer match to the everyday language experience of young adults than older adults (which will include patients suffering from AD).

Similar issues arise regarding measures of AoA which have almost exclusively been derived either from normative data from young children or estimates of AoA made by young adults (e.g., Cuetos, Ellis, \& Alvarez, 1999; Morrison, Chappell, \& Ellis, 1997). Once again, these may not be wholly appropriate when it comes to analyzing data from older people, and $\mathrm{AD}$ patients, who tend to be 70 years or above. Some everyday objects have names that are learned much earlier by today's children than was the case for older adults when they were acquiring their vocabulary (e.g., television or mango) while other objects that have become less familiar in recent times may have been learned earlier in life by people who are now elderly than is the case for modern children (e.g., bellows / fuelle or tripe / callos). Forbes-McKay et al. (2005) used AoA ratings from older adults to analyse the word generation responses of $\mathrm{AD}$ patients but did not directly compare the predictive power of those ratings with ratings from young adults. Cuetos, Samartino, and Ellis (in press) collected AoA ratings for 500 words from healthy adults aged 61 to 85 . Those ratings correlated .772 with ratings obtained from young adults, implying that while there may be some words whose AoA differs markedly across generations, there is also a considerable degree of commonality in the order in which words are learned. Importantly, though, the elderly AoA ratings proved to be more successful than the young adult ratings at predicting which words Spanish 
$\mathrm{AD}$ patients would be able to recognize as familiar in a task where they were required to spot the real word in the presence of three nonword distractors (Cuetos, Herrera, \& Ellis, 2010). The present study compared AoA ratings from younger and older adults in terms of their capacity to predict naming accuracy in $\mathrm{AD}$ patients.

Matched groups of Spanish and English AD patients and healthy controls were asked to name 100 pictures of common objects. This was done as part of a larger study that also looked at reading and writing skills in the two language groups. Differences between Spanish and English in the transparency of their orthographies were expected to generate cross-language effects, but we had no a priori reason to expect that $\mathrm{AD}$ would affect object naming in the two groups differently. Naming accuracy was analysed using measures of visual complexity, imageability, written and spoken word frequency, young and elderly AoA ratings, and word length (in phonemes). We have mentioned word frequency and AoA above. Previous studies have reported either no effect of visual complexity on naming in Alzheimer patients (Rodríguez-Ferreiro et al., 2009) or effects in only a minority of patients (possibly those with more posterior involvement: Kremin et al., 2001; Martinaud et al., 2009), no effect of imageability (whose range is restricted in the case of familiar objects: Cuetos et al., 2005; RodríguezFerreiro et al., 2009) and no effect of word length (Cuetos et al., 2005; Kremin et al., 2001; Rodríguez-Ferreiro et al., 2009; Silveri et al., 2002). Those studies have often used conventional multiple regression. When the aim has been to investigate the properties of objects and their names that predict naming accuracy, the dependent variable has usually been the number of patients in a group that were able to name each item correctly. Here we employed a different statistical method knows as generalized linear mixed-effects modeling (Baayen, 2007; Baayen, Davidson, \& Bates, 2008). This method uses the full data set (i.e., the score for each participant on each item rather than 
the average or total score across participants) and therefore allows the researcher to address effects on naming at the participant and the item level simultaneously.

We used a series of different models to address different aspects of the data. These included a comparison of the ability of written and spoken (subtitle) frequencies, and AoA ratings from younger and older adults, to predict naming accuracy in the AD patients, whether an estimate of the cumulative, lifetime frequency of exposure to words would predict naming better than adult word frequency (which estimates the likely frequency of exposure in a given time), and whether any effects of AoA would survive the inclusion of cumulative frequency as a predictor variable (cf. Zevin \& Seidenberg, 2002). Experimental investigations of object naming and other lexical processing tasks have reported that the benefits of early acquisition remain significant for younger adults even when cumulative frequency is taken into account (Barry, Johnston, \& Wood, 2006; Bonin et al., 2004; Cuetos et al., 2006; Ghyselinck, Lewis, \& Brysbaert, 2004). Other studies have shown that relatively small differences in childhood AoA continue to exert a significant effect on lexical processing speed in older adults despite large differences in the cumulative frequencies of words (De Deyne \& Storms, 2007; Morrison, Hirsh, Chappell, \& Ellis, 2002). Caza and Moscovitch (2005) argued for an effect of cumulative frequency on lexical decision performance in AD patients and healthy older adults on the basis of a comparison of performance on words which had become more common in recent decades and other words that were more common in older than more recent frequency counts.

In addition to investigating naming accuracy, we also explored the extent to which word frequency, AoA and the other variables could the different types of error that $\mathrm{AD}$ patients make in object naming. AD patients are prone to making errors in which they produce the name of a related object (e.g. 'lion' for 'tiger'), a superordinate category 
label (e.g. 'animal' for 'tiger'), or a circumlocution (e.g., 'tomato ... that thing in the salads'). The frequency of these errors has been taken as further evidence that one of the major cognitive impairments suffered by $\mathrm{AD}$ patients is a disintegration of their conceptual-semantic system (Bayles \& Tomoeda, 1983; Hodges, Salmon, \& Butters, 1991; Huff, Corkin, \& Growden, 1986; Smith, Murdoch, \& Chenery, 1989; Hodges et al., 1995). Occasionally, AD patients make visual errors in which they produce the name of an object that is similar in appearance but not in meaning to the pictured object (e.g., 'moon' for 'orange'). As the disease progresses, an increasing number of errors are of the simple 'don't know' (no response) type (Barbarotto et al., 1988, Cuetos et al., 2005). Cuetos et al. (2005) found that the variable that best determines the changes of responses of $\mathrm{AD}$ patients as cognition deteriorates is AoA: there was a perfect progression of change in the response pattern as a function of AoA, from correct responses to semantic errors to 'don't know' responses.

\section{Methods}

\section{Participants}

Two groups of 20 Spanish and 20 English $\mathrm{AD}$ outpatients took part in the experiment. Prior to their inclusion in the study, patients had been diagnosed with AD according to the NINCDS-ADRDA criteria (McKhann et al., 1984; Tierney et al., 1988). Cognitive deficit of the patients was evidenced by their MMSE (Folstein, Folstein, \& McHugh, 1975) scores. Table 1 presents a summary of the participants' socio-demographic and cognitive profiles. There were no significant differences between the two patient groups on any of the variables taken into consideration. For each of the patient groups, a control group of matched healthy seniors was selected. 
Participants with a history of psychiatric disorder, alcohol abuse or sources of cognitive impairment other than $\mathrm{AD}$ were not included in the study. There were also no significant differences between the two patient groups and their controls on any of the socio-demographic variables. All the participants or their caregivers gave their informed consent for the participation in the experiment.

\section{Table 1}

\section{Materials}

A set of object pictures from the Snodgrass and Vanderwart set (1980) was selected for the experiment. The set comprised 100 common objects including a wide variety of animals, fruits, tools, household items, etc. Sixty of the items were manmade objects while 40 were natural objects. Name agreement values for all the pictures were above 85\% both in English and Spanish. English written frequency measures were obtained from CELEX (Baayen et al., 1993) while Spanish measures were taken from Pérez, Alameida and Cuetos (2003). Oral frequency data based on film and television subtitles were taken from Brysbaert and New (2009) and Cuetos et al. (2011). Frequency values were log-transformed for use as predictors. Young adult ratings of AoA were taken from Morrison et al. (1993) and Cuetos et al. (1999). English senior AoA ratings came from a study (Catriona Morrison, personal communication) in which 427 volunteers aged 60 to 90 years rated 200 object names. Spanish senior AoA ratings were taken from the study by Cuetos, Samartino and Ellis (in press) in which healthy Spanish adults aged 61 to 85 years rated 500 words. Last, visual complexity values were obtained from Snodgrass and Vanderwart (1980) and imageability ratings were gathered from LEXESP (Sebastian et al., 2000). A summary of the stimulus characteristics is presented in Table 2 . 


\section{Table 2}

\section{Procedure}

Participants were tested individually. The naming task was presented in the context of a wider test battery. They were instructed to name the depicted objects. In order to make sure that they had understood the instructions, participants were asked to first name a set of practice stimuli. They were then asked to name the experimental target pictures. The experimenter kept a record of every response. AD patients performed the naming task three times in different sessions scheduled one week apart. The healthy control participants performed the task only once.

\section{Results}

Correlations between the different predictor variables, and between the predictor variables and patient naming accuracy are shown in Table 3 for each group and language. The written and oral frequency values correlate quite highly. Traditional written frequency correlates more highly with patient performance than film-based frequency. The young and senior AoA measures also correlate quite highly and show similar correlations with patient performance, with the senior AoA measures showing slightly higher correlations. Frequency and AoA show similar correlations with patient performance. Word length showed a significant raw correlation with naming accuracy for English but not Spanish Alzheimer patients, but also correlated significantly in the English items set with measures of word frequency and AoA. Imageability did not correlate with naming accuracy. VISUAL COMPLEXITY??

Table 3 
The scores obtained by each participant in response to each item were analyzed by means of generalized linear mixed models implemented through the lme4 package (Bates, 2005) in $\mathrm{R}$ ( $\mathrm{R}$ development core team, 2005). Responses that matched the standard picture name of the target name as well as acceptable alternative names, synonyms also used by the control sample, were considered correct $(74.31 \%$ of the patient responses). The other responses were classified according to 5 categories following a simplified version of the scheme applied by Rodríguez-Ferreiro et al. (2009). Errors semantically related to the target name, including coordinates, superordinates and associates, were included under the label "semantic errors" $(12.96 \%$ of total responses). Responses using several words to refer to the target name but not including it were classified as "circumlocutions" (1.34\%). The label "visual error" was applied when the participant produced the name of an object that was visually similar, but not semantically similar, to the target object (1.78\%). It should be noted that many 'semantic' errors also include a high degree of visual (but not phonological) similarity. Responses that shared more than $50 \%$ of the phonemes with the target name, and were not semantically similar to the target object, were considered "phonological errors" $(0.21 \%)$. Lastly, a residual category was created to draw together no-responses and unintelligible utterances under the label "null response" (9.40\%). Table 4 presents examples of the different error categories.

\section{Table 4}

A series of statistical models were used to address different aspects of the data:

Block 1. Comparison of the two patient groups against their corresponding controls and against each other. Mean naming accuracy was $70.3 \%$ for the Spanish AD patients, 93.2\% for the Spanish controls, $78.3 \%$ for the English AD patients, and 95.2\% for the English controls. Two separate models compared the performance of each patient group 
with that of their corresponding control groups, confirming that healthy seniors obtained better scores than $\mathrm{AD}$ patients in both Spanish $(Z=-6.172, p<.001)$ and English groups $(Z=-6.221, p<.001)$. Two further models found no significant difference in accuracy between the Spanish and English AD patients $(Z=-1.196, p=.232)$, or between the Spanish and English controls $(Z=-0.558, p=.577)$.

Block 2. Comparing the impact of written and spoken (subtitle) frequency on naming accuracy in the two AD groups. Across the two groups of $\mathrm{AD}$ patients, both written frequency $(Z=5.391, p<.001)$ and spoken frequency $(Z=4.633, p<.001)$ exerted a significant effect on naming accuracy when considered in the absence of the other predictors. There was no significant effect of language group in either analysis, and no significant interactions involving the language variable, implying that the impacts of the two measures of word frequency were similar for the Spanish and English AD groups.

A further model included the two frequency measures together in order to compare their effects. Collinearity between the two variables was assessed by the calculation of the number $\kappa$ (Belsley, Kuh, \& Welsch, 1980), which in this case was equal to 11 and indicated an acceptably low level of collinearity. The results indicated a significant effect of written frequency across the patient groups $(Z=2.531, p=.011)$ but no effects of oral frequency $(Z=0.35, p=.726)$ or language $(Z=-0.554, p=.580)$, and no significant interaction between language and either written frequency $(Z=0.316, p=$ $.752)$ or spoken frequency $(Z=-0.598, p=.752)$. Hence, written word frequency proved to be a better predictor of naming accuracy than oral (subtitle) frequency for both Spanish and English AD groups. 
Block 3. Comparing the impact of AoA ratings from younger and older adults on naming accuracy in the two AD groups. Across the two groups of AD patients, AoA ratings from both young adults $(Z=-4.350, p<.001)$ and older adults $(Z=-4.858, p<$ .001) exerted a significant effect on naming accuracy when considered in the absence of the other predictors. There was no significant effect of language group in either analysis, and no significant interactions involving the language variable, implying that the impacts of the two measures of AoA were similar for the Spanish and English AD groups.

A further model included the two AoA measures together in order to compare their effects. Collinearity between the two variables was ruled out $(\kappa=10.4)$. There was a highly significant effect of the AoA ratings from older adults $(Z=-2.902, p=.003)$. The additional impact of the AoA ratings from young adults only just attained significance $(Z=-1.964, p=.049)$. There was no significant interaction between language and either senior AoA $(Z=-0.228, p=.820)$ or young adult AoA $(Z=-0.956, p=.339)$. Hence, AoA ratings from older adults proved to be a better predictor of naming accuracy than ratings from younger adults for both Spanish and English AD groups.

Block 4. Investigating the effects of cumulative (lifespan) frequency on naming accuracy in the $A D$ groups. The next set of analyses included estimates of cumulative frequency values as predictors. These were obtained by subtracting the estimated AoA of each word (taken from the older adult ratings) from each patient's age at the time of testing, the multiplying that by each word's written frequency (i.e., using the formula: (patient age - senior AoA) * written frequency). This measure fails to allow for possible changes in the frequency of use of different words over time, but is the best that can be done with the currently-available frequency measures for the two languages. 
A significant effect of cumulative frequency was obtained across the two language groups $(Z=5.229, p<.001)$ which did not interact with language. When senior AoA and written frequency were included in the analysis as additional predictors, the effect of senior AoA was significant $(Z=-3.532, p<.001)$ while the effects of both cumulative frequency $(Z=-0.513, p=.608)$ and written frequency $(Z=1.31, p=.190)$ were nonsignificant. There was no significant effect of language, and no significant interactions involving language. Hence, across the two language groups, the effect of senior AoA remained significant despite the inclusion of both cumulative frequency and written frequency as predictors. We note, though, that high levels of collinearity between cumulative and written frequencies $(\kappa=117.1)$ could be obscuring their effects when entered together in a single analysis. The important point to note here is that the effect of AoA is not eliminated with both written frequency and cumulative frequency were controlled statistically.

Block 5. Investigating the combined effects of visual complexity, imageability, written word frequency, senior AoA, phoneme length and language group on naming accuracy. The next analysis took the best frequency measure (written frequency) and the best AoA measure (senior AoA) and evaluated their effects in combination with visual complexity, imageability and phoneme length. The results are summarized in Table 5. The independent effects of written frequency and senior AoA were significant. The effects of visual complexity, imageability and phoneme length were not significant. Neither the language variable nor its interactions with the other predictors were significant, indicating that the pattern of results was comparable for the Spanish and English patients. Collinearity $(\kappa=60.3)$ was a potential problem in these analyses due to the high correlation between written frequency and imageability, but we note that the 
pattern of results regarding AoA, written frequency and length did not change when imageability was excluded from the analysis.

\section{Table 5}

Block 6. Investigating the combined effects of written word frequency, senior AoA, imageability, phoneme length and language group on semantic and null response errors. The final set of analyses used the same predictors as in the previous block, but this time to predict the numbers of semantic and null response errors (the two main types of error). The results are also shown in Table 5. Semantic error rates were predicted by both written word frequency and senior AoA, meaning that words with both low frequency and late AoA were more prone to semantic errors. Rates of null response errors were predicted by written word frequency only. Once again, the effect of language, and the interactions involving language, were all non-significant, indicating that the pattern of results held equally for Spanish and English patients.

Finally, in order to study how the pattern of error responses might change in the course of cognitive deterioration we compared the proportions of semantic and null responses in patients with relatively high and low accuracy scores. Significant differences $(t(14.23)=-2.898, p=.012)$ appeared between the ratios of semantic to null response of the extreme groups of 15 patients (5 Spanish, 10 English) with the highest accuracy $($ mean $=11.1$, s.d. 12.8) and 15 patients (9 Spanish, 6 English) with the lowest accuracy $($ mean $=1.5$, s.d. 1.2). Hence, as the disease progressed and naming accuracy became worse, the proportion of semantic errors decreased and the proportion of null responses increased.

\section{Discussion}


The present study set out to take a fresh look at the predictors of naming accuracy and errors in a group of 40 patients with AD, half Spanish and half English. At a time when new measures of word frequency based on the spoken language of films and television programmes are being developed, and are being promoted as better predictors of performance in the lexical processing of young adults (Brysbaert \& New, 2009; Cuetos et al., in press; New et al., 2007), we were interested to compare the ability of those contemporary spoken frequency measures against more traditional measures based on written language samples to predict naming accuracy in AD patients. We were also interested to compare the ability of AoA ratings generated by younger and older adults to predict naming. We used those predictors and others such as cumulative frequency, imageability and word length to analyze both the numbers of correct naming responses made to different items and the numbers of semantic and null response errors. Finally, the use of well-matched groups from two different languages and societies allowed us to explore the generalizability of the results we obtained. We employed an improved form of statistical analysis (generalized linear mixed effects modelling) which uses all of the data and makes it possible to explore effects at both the participant and item level simultaneously.

Considering first the effects of word frequency, we note that written and oral (subtitle) frequency measures correlated 0.823 for the Spanish object names and 0.855 for the English object names. For both patient groups, the correlation of naming accuracy with written word frequency was higher than its correlation with oral word frequency (Spanish: 0.339 vs 0.251; English 0.549 vs 0.496 respectively). Both frequency measures predicted naming accuracy when considered in isolation, but when they were compared directly in the same analysis (block 2), only written frequency was 
significant. This is the opposite of what has been reported for word recognition in young English- and Spanish-speaking adults where oral (subtitle) frequency out-performs measures based on samples of written language (Brysbaert \& New, 2007; Cuetos et al., 2011; New et al., 2007). Brysbaert and New (2009) noted, though, that subtitle frequencies were less good predictors of lexical decision speed in older adults than young adults. Both Spanish and English societies have undergone major changes since the older participants in the present study were children or young adults some $30-60$ years ago. Older people are selective in the films and television programmes they choose to watch. The film and television samples used to collect current oral frequency measures may not be representative of the vocabulary of the daytime television programmes and movies that older people prefer. Words cited by Brysbaert and New (2009) as showing higher subtitle frequencies than in the written frequency count of Kucera and Francis (1965) include 'freak', 'trash', 'swear', 'jerk', 'cute', 'wow' and 'ass', illustrating vividly the extent to which modern television programmes and (especially) movies are aimed at young adults and use a young adult's vocabulary. It is still possible that a subtitle frequency count based on the films and programmes older people actually watching could be a better predictor of their naming performance than written language samples.

AoA ratings from young and older adults correlated 0.501 for the Spanish object names and 0.607 for the English object names. The correlations with naming accuracy slightly favoured senior AoA over young adult AoA (Spanish: -0.489 vs -0.471; English $-0.497 v s-0.43$ respectively). The similarity in performance for young and senior AoA may reflect the fact that set of object pictures used in the present study did not include objects whose AoA values were substantially different for older compared with younger people. As with the two word frequency measures, the two AoA measures were both 
able to predict naming accuracy when considered in isolation, but when taken together, senior AoA out-performed young adult AoA (block 3). Cuetos et al. (in press) similarly found that senior AoA ratings were better than young adult ratings at predicting word recognition in $\mathrm{AD}$ patients. Taken together, the results of the present study and that of Cuetos et al. (in press) indicate that researchers interested in analyzing the effects of AoA in AD patients, or in other older participant groups such as stroke patients or healthy elderly adults, would be advised to obtain AoA ratings from age-matched rather than young adults.

The joint effects of frequency and AoA in the present study support the findings of Tippett et al. (2007) and Rodríguez-Ferreiro et al. (2009) who also reported independent effects of those two variables on object naming in AD. Problems with the frequency measures used may explain the failure of Silveri et al. (2002) and Cuetos et al. (2005) to obtain a frequency effect over and above the AoA effect. The effect of AoA on naming accuracy in $\mathrm{AD}$ patients survived the inclusion of cumulative frequency as a predictor, lending further support to the claim that the benefits of early acquisition cannot be accounted for in terms of lifespan exposure to different words (cf. Barry et al., 2006; Bonin et al., 2004; Cuetos et al., 2006; Ghyselinck et al., 2004). The AoA effect (and the frequency effect) also survived the inclusion into the analyses of imageability and phoneme length, providing further evidence that the advantages conferred upon representations by AoA and frequency are genuine advantages of early over late acquisition, and high over low frequency of exposure to words.

Other studies have also reported that visual complexity, imageability and length do not influence object naming in AD once other factors are controlled (Cuetos et al., 2005; Rodríguez-Ferreiro et al., 2009; Silveri et al., 2002; Tippett et al., 2007). The absence of effects of visual complexity and name length on performance are compatible with the 
claim that the problems experienced by $\mathrm{AD}$ patients in object recognition and naming are primarily semantic rather than perceptual or phonological (speech related). The interpretation of the lack of an imageability effect on naming is, as always, limited by the restricted range of imageability values for object names (which all tend to be highly imageable). Determining whether or not imageability affects lexical processing in AD will depend on studies that use a wider range of vocabulary than is possible with object naming.

Regarding the production of erroneous responses, as in previous studies (Barbarotto et al., 1998, Cuetos et al., 2005), semantic and null response errors were the most common error type produced by the patients. Other kinds of errors, like visually or phonologically related responses were scarcely produced. The appearance of semantic errors was predicted by both AoA and frequency which situates their origin in a malfunction of the semantic and lexical systems, where these two variables have their influence. Our conclusions are in line with those drawn by previous studies that also pointed out the existence of problems at the semantic system and in the lexical access in AD patients (Hodges \& Patterson, 1995; Hodges et al., 1996; Hodges, Salmon \& Butters, 1991, 1992). A patient with AD may have difficulty recognizing a relatively unfamiliar, late acquired object (cf. Holmes et al., 2006). The patient may access the meaning of a more familiar, earlier acquired object that is similar in appearance, resulting in a semantic error, or the patient may access only a vague meaning, or no meaning at all, resulting in a null response error. As the disease progresses, more and more objects activate vague or no meanings, so the proportion of semantic errors decreases and the proportion of null responses increases. The AoA and frequency characteristics of the items being attempted determine the occurrence of those different forms of error as well as the occurrence of correct responses. 
The Spanish and English patients who participated in the present study were matched on socio-economic factors and on overall naming accuracy. They showed the same pattern of performance when it came to the impact of AoA, word frequency and other factors on naming accuracy and errors. For AD patients at least, the results seem to be consistent across Spanish, English and Italian. A much wider range of languages has been tested in explorations of the factors influencing the speed with which healthy young adults can name object pictures. One again, the core factors of AoA and word frequency appear consistently and seem to affect all languages to a similar extent (e.g., Cuetos et al., 1999; Ellis \& Morrison, 1998; Ghyselinck et al., 2004). This may be because while languages differ considerably in the way that orthography relates to phonology and meaning, the mappings of object meanings onto names are arbitrary in all languages. Arbitrary mappings learned over a period of years and experienced more or less often in adulthood create the perfect conditions for the emergence of representations for words learned early in life and reinforced with high frequency that are stronger and more resistant to the effect of brain damage than are the representations for words learned later in life and reinforced less often (Ellis, in press; Ellis \& Lambon Ralph, 2000; Lambon Ralph \& Ehsan, 2006). More research is needed involving a wider range of cultures and languages, but we suggest that with accurate measures of AoA and word frequency, the effects reported here may prove to be universal. 
ADD these

Martinaud, O., Opolczynski, G., Gaillard, M.-J., \& Hannequin, D. (2009). Relevant category-specific effects on naming in Alzheimer's disease. Dementia and Geriatric Cognitive Disorders, 28, 413-418.

References

Baayen, R.H. (2007). Analyzing linguistic data. Cambridge, Cambridge University Press.

Baayen, R.H., Davidson, D.J. and Bates, D.M. (2008). Mixed-effects modeling with crossed random effects for subjects and items. Journal of Memory and Language, 59, 390-412.

Baayen, R.H, Piepenbrock, R., \& van Rijn, H. (1993). The CELEX lexical database $(C D-R O M)$. University of Pennsylvania, PA: Linguistic Data Consortium.

Balota, D. A., Cortese, M. J., Sergent-Marshall, S. D., Spieler, D. H., \& Yapp, M. J. (2004). Visual word recognition for single syllable words. Journal of Experimental Psychology: General, 133, 283-316.

Balota, D. A., Yapp, M. J.. Cortese, M. J., Hutchinson, K. A., Kessler, B., Loftis, B., et al. (2007). The English Lexicon Project. Behavior Research Methods, 39, 445459.

Barbarotto, R., Capitani, E., Jori, T., Laiacona, M., \& Molinari, S. (1998). Picture naming and progression of Alzheimer's disease: an analysis of error types. Neuropsychologia, 36, 397-405.

Barker, M. \& Lawson, J. (1968). Nominal aphasia in dementia. British Journal of Psychiatry, 114, 1351-1356.

Barry, C., Johnston, R. A., \& Wood, R. F. (2006). Effects of age of acquisition, age, and repetition priming on object naming. Visual Cognition, 13, 911-927.

Bates, D. M. (2005). Fitting linear mixed models in R. R News, 5(27-30).

Bayles, K. A. \& Tomoeda, C. K. (1983). Confrontational naming impairment in dementia. Brain and Language, 19, 98-114.

Belsley, D. A., Kuh, E., \& Welsch, R. E. (1980). Regression diagnostics. Identifying influential data and sources of collinearity. New York: Wiley. 
Bonin, P., Barry, C., Meot, A. \& Chalard, M. (2004). The influence of age of acquisition in word reading and other tasks: A never ending story? Journal of Memory and Language 50, 456-476

Brysbaert, M. \& Cortese, M.J (2011). Do the effects of subjective frequency and age of acquisition survive better word frequency norms? The Quarterly Journal of Experimental Psychology, 64, 545-559

Brysbaert, M., \& New, B. (2009). Moving beyond Kucera and Francis: A critical evaluation of current word frequency norms and the introduction of a new and improved word frequency measure for American English. Behavior Research Methods, 41, 977-990

Caza, N. \& Moscovitch, M (2005). Effects of cumulative frequency, but not of frequency trajectory, in lexical decision times of older adults and patients with Alzheimer's disease. Journal of Memory and Language 53, 456-471

Cuetos, F., Alvarez, B., González-Nosti. M., Meot, A \& Bonin, P. (2006). Determinants of lexical access in speech production: Role of word frequency and age of acquisition. Memory and Cognition, 34, 999-1010.

Cuetos, F, Ellis, A. \& Alvarez, B. (1999). Naming times for the Snodgrass and Vanderwart pictures in Spanish. Behavior Research Methods, Instruments and Computers, 31, 650-658.

Cuetos, F., González-Nosti, M., Barbón, A., \& Brysbaert, M. (2011). SUBTLEX-ESP: Spanish word frequencies based on film subtitles. Psicológica, 32, 133-143.

Cuetos, F., Gonzalez-Nosti, M., \& Martinez, C. (2005). The picture-naming task in the analysis of cognitive deterioration in Alzheimer's disease. Aphasiology, 19, 545557.

Cuetos, F., Herrera, E. \& Ellis, A.W. (2010). Impaired word recognition in Alzheimer's disease: the role of age of acquisition. Neuropsychologia, 48, 3329-3334.

Cuetos, F., Rodríguez-Ferreiro, J., \& Menéndez, M. (2009). Semantic markers in the diagnosis of neurodegenerative dementias. Dementia and Geriatric Cognitive Disorders, 28, 267-274.

Cuetos, F., Samartino, T. \& Ellis, A.W. (in press). Age acquisition norms from elderly Spanish people: characteristics and the prediction of word recognition performance in Alzheimer's disease. Psicologica

De Deyne, S., \& Storms, G. (2007). Age-of-acquisition differences in young and older adults affect latencies in lexical decision and semantic categorization. Acta Psychologica, 124, 274-295.

Ellis, A. W. (2011). The acquisition, retention and loss of vocabulary in aphasia, dementia and other neuropsychological conditions. In M. Faust (Ed.). Handbook of the neuropsychology of language, vol. 2 (pp. 637-660). Oxford: Blackwells. 
Ellis, A. W., \& Lambon Ralph, M. A. (2000). Age of acquisition effects in adult lexical processing reflect loss of plasticity in maturing systems: Insights from connectionist networks. Journal of Experimental Psychology: Learning, Memory, and Cognition, 26, 1103-1123.

Ellis, A. W., \& Morrison, C. M. (1998). Real age of acquisition effects in lexical retrieval. Journal of Experimental Psychology: Learning, Memory, and Cognition, $24,515-523$.

Folstein, M. J., Folstein, S. E., \& Mchugh, P. R. (1975). "Mini-mental state": a practical method for grading the cognitive state of the patients for the clinicians. Journal of Psychiatric Research, 12, 189-198.

Forbes-McKay, K.E., Ellis., A.W., Shanks, M.F. \& Venneri, A. (2005). The age of acquisition of words produced in a semantic fluency task is highly predictive of early Alzheimer's disease. Neuropsychologia, 43, 1625-1632

Gale, T. M., Irvine, K., Laws, K. R., \& Ferrissey, S. (2009). The naming profile in Alzheimer patients parallels that of elderly controls. Journal of Clinical and Experimental Neuropsychology, 31, 565-574.

Garrard, P., Lambon Ralph, M. A., Patterson, K., Pratt, K. H., \& Hodges, J. R. (2005). Semantic feature knowledge and picture naming in dementia of Alzheimer's type: A new approach. Brain and Language, 93, 79-94.

Ghyselinck, M., Lewis, M. B., \& Brysbaert, M. (2004). Age of acquisition and the cumulative-frequency hypothesis: A review of the literature and a new multitask investigation. Acta Psychologica, 115, 43-67.

Hodges, J. R., Graham, N., \& Patterson, K. (1995). Charting the progression in semantic dementia: Implications for the organisation of semantic memory. Memory, 3, 463-495.

Hodges, J. R., \& Patterson, K. (1995). Is semantic memory consistently impaired early in the course of Alzheimer's disease? Neuroanatomical and diagnosic implications. Neuropsychologia, 33, 441-459.

Hodges, J. R., Patterson, K., Graham, N., \& Dawson, K. (1996). Naming and knowing in dementia of Alzheimer's type. Brain and Language, 54, 302-325.

Hodges, J. R., Salmon, D. P., \& Butters, N. (1991). The nature of the naming deficit in Alzheimer's and Huntingdon's disease. Brain, 114, 1547-1559.

Hodges, J. R., Salmon, D. P., \& Butters, N. (1992). Semantic memory impairment in Alzheimer's disease: failure of access of degraded knowledge?

Neuropsychologia, 30, 301-314.

Holmes, S. J., Fitch, F. J., \& Ellis, A. W. (2006). Age of acquisition affects object recognition and picture naming in patients with Alzheimer's disease. Journal of Clinical and Experimental Neuropsychology, 13, 884-910 
Huff, F. J., Corkin, S., \& Growden, J. H. (1986). Semantic impairment and anomia in Alzheimer's disease. Brain and Language, 28, 235-249.

Kirshner, H. S., Webb, W. G., \& Kelly, M. P. (1984). The naming disorder of dementia. Neuropsychologia, 22, 23-30.

Kremin, H., Perrier, D., De Wilde, M., Dordain, M., Le bayon, A., Gatignol, P. et al. (2001). Factors predicting success in picture naming in Alzheimer's disease and primary progressive aphasia. Brain and Cognition, 46, 180-184.

Lambon Ralph, M. A., \& Ehsan, S. (2006). Age of acquisition effects depend on the mapping between representations and the frequency of occurrence: Empirical and computational evidence. Visual Cognition, 13, 292-248.

Lambon Ralph, M.A., Graham, K.S, Ellis, A.W. \& Hodges, J.R. (1998) Naming in dementia: What matters? Neuropsychologia, 36, 775-784.

Lambon Ralph, M. A., Patterson, K., \& Hodges, J. R. (1997). The relationship between naming and semantic knowledge for different categories in dementia of Alzheimer's type. Neuropsychologia, 35, 1251-1260.

McKhann, G., Drachman, D., Folstein, M., Katzman, R., Price, D., \& Stadlan, E. M. (1984). Clinical diagnosis of Alzheimer's disease: report of the NINCDSADRDA work group under the auspices of the Department of Health and Human Services Task Force on Alzheimer's disease. Neurology, 34, 939-944.

Morrison, C. M., Chappell, T. D., \& Ellis, A. W. (1997). Age of acquisition norms for a large set of object names and their relation to adult estimates and other variables. The Quarterly Journal of Experimental Psychology, 50A, 528-559.

Morrison, C. M., Hirsh, K. W., Chappell, T. D., \& Ellis, A. W. (2002). Age and age of acquisition: An evaluation of the cumulative frequency hypothesis. European Journal of Cognitive Psychology, 14, 435-459.

New, B., Brysbaert, M., Veronis, J., \& Pallier, C. (2007). The use of film subtitles to estimate word frequencies. Applied Psycholinguistics, 28, 661-677

Pérez, M. A., Alameda, J. R., \& Cuetos, F. (2003). Frecuencia, longitud y vecindad ortográfica de las palabras de 3 a 16 letras del Diccionario de la Lengua Española (RAE, 1992). Revista Española de Metodología Aplicada, 8, 1-20.

R development core team. (2005). R: A language and environment for statistical omputing (Version 2.5.1). Vienna: R foundation for statistical computing.

Rodríguez-Ferreiro, J., Davies, R. A. I., González-Nosti, M., Barbón, A., \& Cuetos, F. (2009). Name agreement, frequency and age of acquisition, but not grammatical class, affect object and action naming in Spanish speaking participants with Alzheimer's disease. Journal of Neurolinguistics, 22(1), 37-54.Sebastián, N., Martí, M.A., Carreiras, M.F. \& Cuetos, F. (2000) LEXESP: Léxico Informatizado del español. Barcelona, Ediciones de la Universitat de Barcelona. 
Silveri, M. C., Cappa, A., Mariotti, P., \& Puopolo, M. (2002). Naming in patients with Alzheimer's disease: Influence of age of acquisition and categorical effects. Journal of Clinical and Experimental Neuropsychology, 24, 755-764.

Smith, S. R., Murdoch, B. E., \& Chenery, H. J. (1989). Semantic abilities in dementia of the Alzheimer type: 1. Brain and Language, 36, 314-324.

Snodgrass, J. G. \& Vanderwart, M. (1980). A standardized set of 260 pictures: Norms for name agreement, image agreement, familiarity and visual complexity. Journal of Experimental Psychology: Human Learning and Memory, 6, 174215.

Tierney, M. C., Fisher, R. H., Lewis, A. J., Zorzitto, M. L., Snow, W. G., \& Reid, D. W. (1988). The NINCDS-ADRDA work group criteria for the clinical diagnosis of probable Alzheimer's disease: A clinico-pathologic study of 57 cases. Neurology, 38, 359-364.

Tippett, L.J., Meier, S.L, Blackwood, K. \& Diaz-Asper, C. (2007). Category-specific deficits in Alzheimer's disease: Fact or artefact? Cortex, 43, 907-920.

Vogel, A., Gade, A., Stokholm, J. \& Waldemar, G. (2005). Semantic memory impairment in the earlist phases of Alzheimer's disease. Dementia and Geriatric Cognitive Disorders, 19, 76-81.

Zevin, J.D. \& Seidenberg, M.S. (2002). Age of acquisition effects in reading and other tasks. Journal of Memory and Language, 47, 1-29. 
Table 1. Summary of the participants' demographic characteristics

\begin{tabular}{|c|c|c|c|c|c|}
\hline \multirow{4}{*}{ Spanish } & & $\begin{array}{c}\text { Sample } \\
\text { size }\end{array}$ & Age & $\begin{array}{c}\text { Years of } \\
\text { education }\end{array}$ & MMSE \\
\hline & & (males) & mean (s.d.) & mean (s.d.) & mean (s.d.) \\
\hline & patients & $20(10)$ & $74.2(7.25)$ & $8.6(2.52)$ & $17.2(2.72)^{\star \star \star}$ \\
\hline & control & $20(10)$ & $71.5(7.97)$ & $7.5(2.11)$ & $28.3(1.01)$ \\
\hline
\end{tabular}

\section{English}

$\begin{array}{llllc}\text { patients } & 20(10) & 75.6(7.75) & 9.7(1.38) & 17.1(2.65)^{\star * *} \\ \text { controls } & 20(10) & 73.6(8.86) & 10.4(1.18) & 27.7(1.3)\end{array}$

${ }^{* * *} p<.001 ;{ }^{* *} p<.01 ;{ }^{*} p<.05$; in the comparison against the control group 
Table 2. Summary of the characteristics of the stimuli.

\begin{tabular}{lcccc}
\hline & \multicolumn{2}{c}{ English } & \multicolumn{2}{c}{ Spanish } \\
& mean & $($ range $)$ & mean & $($ range $)$ \\
Visual & 2.7 & $(1-4.35)$ & 2.7 & $(1-4.35)$ \\
Complexity & & & & \\
Imageability & 6.3 & $(5.5-6.9)$ & 6.8 & $(6-7)$ \\
Phonemes & 4.1 & $(1-9)$ & 5.6 & $(3-10)$ \\
Written & 31.2 & $(1-250)$ & 32 & $(1-286)$ \\
Frequency & & & & \\
Oral Frequency & 33.5 & $(1-330)$ & 26 & $(1-253)$ \\
Young AoA & 2.3 & $(1.1-3.8)$ & 2.3 & $(1.3-4.3)$ \\
Senior AoA & 3 & $(1.6-7)$ & 4 & $(2.6-6.6)$
\end{tabular}


Table 3. Correlations between the different predictors and accuracy scores for the Alzheimer patients.

\begin{tabular}{|c|c|c|c|c|c|c|c|c|c|}
\hline \multicolumn{10}{|l|}{ English } \\
\hline & Imageability & Phonemes & WFrequency & OFrequency & YAOA & & SAOA & & $\begin{array}{l}\text { Visual } \\
\text { Complexity }\end{array}$ \\
\hline Accuracy & 0.010 & $-0.397^{* * *}$ & $0.549^{* * *}$ & $0.496 * * *$ & 0.430 & *** & 0.497 & $* * *$ & -0.134 \\
\hline Imageability & & 0.074 & 0.040 & 0.102 & 0.380 & *** & 0.032 & & 0.192 \\
\hline Phonemes & & & $-0.417^{* \star *}$ & $-0.391^{* \star *}$ & 0.297 & *** & 0.403 & $\star \star \star *$ & $0.259^{\star \star}$ \\
\hline WFrequency & & & & $0.855^{* * *}$ & 0.458 & *** & 0.322 & ** & -0.119 \\
\hline OFrequency & & & & & 0.499 & *** & 0.293 & $* *$ & -0.091 \\
\hline YAoA & & & & & & & 0.607 & $* * *$ & 0.123 \\
\hline SAOA & & & & & & & & & $0.308^{* *}$ \\
\hline \multicolumn{10}{|l|}{ Spanish } \\
\hline & Imageability & mes & WFrec & $c y$ & & & & & Visual \\
\hline Accuracy & 0.218 * & 0.016 & $0.339^{* * *}$ & $0.251 *$ & 0.471 & *** & 0.480 & $* * *$ & -0.145 \\
\hline Imageability & & -0.063 & 0.047 & -0.003 & 0.249 & * & 0.375 & $* * *$ & -0.076 \\
\hline Phonemes & & & -0.139 & -0.107 & 0.265 & ** & 0.160 & & 0.080 \\
\hline WFrequency & & & & $0.823^{* * *}$ & 0.317 & ** & 0.279 & $\star \star \star ~$ & -0.174 \\
\hline OFrequency & & & & & 0.345 & *** & 0.170 & & -0.073 \\
\hline YAoA & & & & & & & 0.501 & *** & 0.138 \\
\hline SAOA & & & & & & & & & $0.302^{* *}$ \\
\hline
\end{tabular}

${ }^{*} \mathrm{p}<.05 ;{ }^{* *} \mathrm{p}<.01 ;{ }^{* * *} \mathrm{p}<.001$ in the correlation analyses 
Table 4. Examples of errors produced by English and Spanish patients.

$\begin{array}{lllll} & \text { English } & & \text { Spanish } & \\ & \text { Target } & \text { Response } & \text { Target } & \text { Response } \\ \text { Semantic } & \text { cow } & \text { milk } & \text { plátano (banana) } & \text { melón (mellon) } \\ \text { Circumlocution } & \text { button } & \text { put things } & \text { payaso (clown) } & \text { el que te hace reír } \\ & & \text { through and } & & \text { (someone that } \\ & & \text { pull } & & \text { makes you laugh) } \\ \text { Visual } & & \text { heart } & \text { cereza (cherry) } & \text { pelota (ball) } \\ \text { Phonological } & & & \text { trompeta(trumpet) } & \text { tormenta (storm) }\end{array}$


Table 5. $\mathrm{Z}$ values and significance levels for the accuracy and errors models.

\begin{tabular}{lccc} 
& Accuracy & Semantic & \multicolumn{1}{l}{ Null } \\
Language & -0.77 & -0.357 & 1.699 \\
Visual Complexity & 0.404 & 0.631 & -0.62 \\
Imageability & -0.236 & 0.296 & 0.467 \\
Frequency & $4.011{ }^{* * *}$ & $-3.256{ }^{* *}$ & $-2.46{ }^{* *}$ \\
sAoA & $-3.135 * *$ & $2.169 *$ & 1.77 \\
Phonemes & -0.804 & 0.4 & 0.563 \\
Interactions with Language & & & \\
Visual Complexity & 0.049 & 0.604 & -0.85 \\
Imageability & 0.794 & 0.284 & -1.64 \\
Frequency & -0.33 & 0.736 & 0.166 \\
sAoA & -1.069 & 0.157 & 1.329 \\
Phonemes & 1.754 & -1.345 & -0.47 \\
$* * * p<.001 ;{ }^{* *} \mathrm{p}<.01 ;{ }^{*} \mathrm{p}<.05 ;$ & & &
\end{tabular}

